\title{
Gambaran Kestabilan Suhu Tubuh Bayi Baru Lahir Yang Dilakukan Inisiasi Menyusu Dini (IMD) (Di Ruang Mina RS Muhammadiyah Tuban)
}

\author{
${ }^{1}$ Umu Qonitun, ${ }^{2}$ Sri Utaminingsih \\ ${ }^{1}$ Dosen Prodi DIII Kebidanan STIKES Nahdlatul Ulama Tuban \\ ${ }^{2}$ Mahasiswa Prodi DIII Kebidanan STIKES Nahdlatul Ulama Tuban
}

\begin{abstract}
ABSTRAK
Hipothermia adalah suhu bayi $<36,5^{\circ} \mathrm{C}$. Disamping sebagai suatu gejala, hipothermia dapat merupakan awal penyakit yang berakhir dengan kematian. Salah satu cara pencegahan hipothermia pada bayi baru lahir adalah dengan penerapan Inisiasi Menyusu Dini (IMD). Oleh karena itu penelitian ini bertujuan untuk mengetahui gambaran kestabilan suhu tubuh bayi baru lahir yang dilakukan Inisiasi Menyusu Dini (IMD) berdasarkan suhu sebelum dilakukan IMD dan suhu sesudah dilakukan IMD di Ruang Mina RS Muhammadiyah Tuban.

Desain penelitian ini menggunakan desain deskriptif.Populasi dalam penelitian ini adalah seluruh bayi baru lahir normal yang dilakukan IMD bulan Mei 2018 sebanyak 29 bayi, sedangkan sampelnya yaitu sebagian bayi baru lahir normal yang dilakukan IMD yang memenuhi kriteria inklusi sebanyak 29 bayi. Teknik sampling yang digunakan adalah purposive sampling dan sampel diambil dari hasil observasi (data primer) yang ditulis dalam lembar observasi dengan menggunakan instrumen penelitian berupa thermometer axilla digital. Data di analisis dengan analisa univariat.

Hasil penelitian menunjukkan bahwa hampir seluruhnya sebanyak $25(86,21 \%)$ bayi baru lahir sebelum dilakukan IMD mempunyai suhu yang tidak stabil, dan seluruhnya sebanyak 29 (100\%) bayi baru lahir sesudah dilakukan IMD mempunyai suhu yang stabil.

Dari uraian di atas dapat disimpulkan bahwa penerapan Inisiasi Menyusu Dini (IMD) sangat efektif untuk membantu kestabilan suhu tubuh bayi baru lahir dengan harapan hipotermia dapat dicegah sedini mungkin, untuk itu diharapkan tenaga kesehatan khususnya bidan dapat menerapkan Inisiasi Meyusu Dini (IMD) pada semua bayi baru lahir sesuai dengan prosedur.
\end{abstract}

\section{Kata Kunci : Kestabilan Suhu Bayi Baru Lahir, Inisiasi Menyusu Dini}

\section{ABSTRACT}

Hypothermia is an infant temperature $<36,5^{\circ} \mathrm{C}$. Aside from being a symptom, hypothermia can be the beginning of disease that ends in death. One of the ways of preventing hypothermia in neonatus is by applying early initiation breastfeeding. This resarch had aim to description termoregulator neonatus stability that applied early initiation breast feeding base on before and after temperature of neonatus at Mina ward Muhammadiyah Hospital Tuban.

Design of this research used descriptive design. Population of this researh was normal new baby born delivery was appliying early initiation breastfeeding on May 2018 (29 baby). The sample was normal newborn baby delivery that equall with inclution category ( 29 baby). Sampling technique used purposive sampling and the sample is taken from observation (primary data) written in observation sheet using the research instrument in the form of axilla digital thermometer. Data were analyzed by univariate analysis.

Result of this research show nearly all as much $25(86,21 \%)$ new born baby before applied early initiation breast feeding had unstabil body temperature. All as much 29 (100\%) new born baby after applied early initiation breast feeding had stabil body temperature.

Research conclutions early initiation breast feeding efective to support stability of newborn baby temperature whith aimed hypotermia could early prevention. Resercher hope every health provider specially midwife could apply early initiation breast feeding to all neonatus as well as SOP.

\section{Key Word: Stability New Baby Born Temperature, Early Initiation Breast Feeding}




\section{PENDAHULUAN}

Sebagian besar dari masalah bayi baru lahir adalah spesifik timbul pada periode perinatal. Masalah-masalah ini bukan hanya bisa menyebabkan kematian, tetapi juga besarnya angka kecacatan dan angka penyakit. Masalah ini salah satunya disebabkan oleh kebersihan yang tidak terjaga selama proses kelahiran, kurangnya asuhan BBL serta asuhan yang pilih kasih. Kematian dikalangan bayi baru lahir sudah demikian seringnya hingga hal tersebut diterima sebagai suatu hal yang rutin oleh masyarakat (WHO, $1996: 11-2$ ).

Seperti yang terjadi dihampir semua negara didunia, kesehatan bayi cenderung kurang mendapat perhatian dibandingkan umur-umur lainnya. Padahal data WHO (2002) menunjukkan angka tersebut sangat memprihatinkan, yang dikenal dengan "Fenomena $2 / 3$ " yaitu $2 / 3$ kematian bayi (umur 0-1 tahun) terjadi pada masa neonatal (BBL 028 hari), dan $2 / 3$ kematian pada masa neonatal dini terjadi pada hari pertama. Oleh karena itu 1 minggu pertama dari kelahiran adalah masa yang paling kritis bagi kehidupan seorang bayi (Kokom, 2007). Berdasarkan data WHO, di Indonesia sebanyak 100.454 bayi 028 hari (neonatal) meninggal setiap tahun. Ini berarti 275 neonatal meninggal setiap hari, atau lebih kurang 184 neonatal dini meninggal setiap hari, atau setiap 1 jam 8 bayi neonatal dini meninggal, atau setiap 7,5 menit 1 bayi neonatal dini meninggal (Kokom, 2007).

Kematian neonatal dini yang telah disebutkan sebelumnya lebih banyak disebabkan secara langsung karena asfiksia, infeksi (sepsis dan infeksi saluran pernafasan), prematuritas dan hypothermia (Kokom, 2007). Meskipun hanya sedikit sekali dan hampir tidak ada data yang tersedia mengenai berapa banyak kematian BBL yang disebabkan hipothermia, namun hipothermia pada BBL merupakan masalah dunia, bahkan di wilayah yang beriklim panas ataupun tropis. Karena BBL yang menderita hipothermia segera setelah lahir kemungkinan mengalami hipothermia selama 24 jam berikutnya. Selain itu, BBL yang mengalami asfiksia saat lahir juga akan lebih besar kemungkinannya untuk mengalami hipothermia dan pada akhirnya akan memperparah asfiksia bayi (WHO, 1996 : 11-3).
Adapun mekanisme atau proses penurunan suhu pada BBL, yaitu segera setelah dilahirkan, suhu BBL akan turun. Bayi yang masih basah bisa kehilangan panas cukup banyak untuk membuat suhu tubuhnya turun sampai sebanyak $2-4^{\circ} \mathrm{C}\left(3,6-7,2^{\circ} \mathrm{C}\right)$. Karena dalam keadaan basah, maka bayi tersebut akan kehilangan sebagian besar panas tubuhnya melalui penguapan (evaporasi) dari permukaan kulit yang basah, persentuhan dengan bendabenda yang dingin (konduksi), persentuhan dengan udara dingin (konveksi), atau persentuhan dengan benda-benda yang bersuhu lebih rendah di sekitarnya (radiasi) (WHO, 1993 : 10-7).

Penurunan suhu pada bayi tersebut terjadi pada menit-menit ke 10-20 setelah kelahiran. Hal ini disebabkan oleh ketidakmampuan bayi untuk menghasilkan panas yang cukup untuk mengimbangi hilangnya panas saat kelahiran. Selain itu suhu dingin dan luar permukaan yang lebih besar dibandingkan dengan tubuhnya yang kecil serta kepalanya yang secara proporsional lebih besar, juga bisa menyebabkan turunnya suhu pada bayi (WHO, 1993 : 10-7).

Adapun dampak atau konsekuensi dari hipothermia biasanya sangat parah. BBL yang hipothermia akan menderita hipoglycemia (gula darah rendah) serta asidosis metabolis, sebab mereka akan mencoba untuk menghasilkan panas guna mempertahankan suhu tubuhnya. Bila terjadi hipoglycemia berat akan menyebabkan gagal kegawatan pernafasan serta penggumpalan darah yang abnormal. BBL yang menderita cedera dingin dan hipothermia akan menghadapi resiko yang lebih tinggi lagi terkena infeksi, penguningan (jaundice), serta pulmonaria hemorrhage (perdarahan paru-paru). BBL dengan hipothermia akan lebih besar kemungkinannya meninggal dibanding dengan BBL yang tidak mengalami hypothermia (WHO, $1993: 10-8$ )

Berdasarkan data yang ada di Dinas Kesehatan Kabupaten Tuban, pada tahun 2014 terdapat 186 kematian bayi diantara 16.995 kelahiran hidup di Kabupaten Tuban atau AKB (dilaporkan) sebesar 11 per 1.000 kelahiran hidup dan semuanya itu salah satunya disebabkan oleh hypothermia. Berdasarkan survei awal di RS Muhammadiyah Tuban didapatkan $20 \mathrm{BBL}$, ternyata ada $9 \mathrm{BBL}$ yang mengalami hypothermia. Adapun 
pendistribusiannya adalah bayi dengan suhu $<36^{\circ} \mathrm{C}$ (hipothermia) ada \pm 8 bayi (40\%), suhu antara $36,5-37,5^{\circ} \mathrm{C}$ (normal) ada \pm 10 bayi (50\%), suhu $>37,5^{\circ} \mathrm{C}$ (hiperthermia) ada \pm 2 bayi (10\%).

Untuk pencegahan hipothermia pada BBL bisa dilakukan dengan cara Inisiasi Menyusu Dini (IMD) yaitu dilakukan segera setelah bayi lahir, kemudian bayi dikeringkan kecuali kedua telapak tangan dan diletakkan didada ibu untuk skin to skin selama minimal satu jam. Dada ibu sebagai stabilisator suhu yang dapat menghangatkan tubuh bayi yang beresiko kedinginan karena adaptasi dengan udara luar kandungan pasca bersalin (Vivian, 2010).

Dari uraian di atas dapat disimpulkan bahwa terdapat $40 \%$ BBL yang mengalami hypothermia di RS Muhammadiyah Tuban. Sehingga peneliti tertarik untuk mengetahui bagaimana gambaran kestabilan suhu tubuh bayi baru lahir yang dilakukan Inisiasi Menyusu Dini (IMD) di Ruang Mina RS Muhammadiyah Tuban.

\section{METODE DAN BAHAN}

Penelitian ini merupakan penelitian deskriptif dimana peneliti hanya bermaksud mendiskripsikan (memaparkan) tentang gambaran kestabilan suhu tubuh bayi baru lahir yang dilakukan Inisiasi Menyusu Dini (IMD).

Populasi pada penelitian ini berjumlah 29 bayi. Sampel pada penelitian ini berjumlah 29 bayi. Tehnik pengambilan sampel purposive sampling yaitu metode penetapan sampel dengan memilih beberapa sampel tertentu yang dinilai sesuai dengan tujuan atau masalah penelitian dalam sebuah populasi (Nursalam, 2008).

Alat pengumpulan data pada penelitian ini adalah Thermometer Axilla Digital. Analisa data penelitian ini menggunakan analisa univariat.

\section{HASIL DAN \\ PEMBAHASANPENELITIAN}

Penelitian ini dilakukan di Ruang Mina RS Muhammadiyah Tuban. Responden pada penelitian ini adalah sebagian bayi baru lahir normal yang dilakukan IMD yang memenuhi kriteria inklusi.

\section{DATA KHUSUS}

1. Kestabilan Suhu Tubuh Bayi Baru Lahir Sebelum Dilakukan IMD

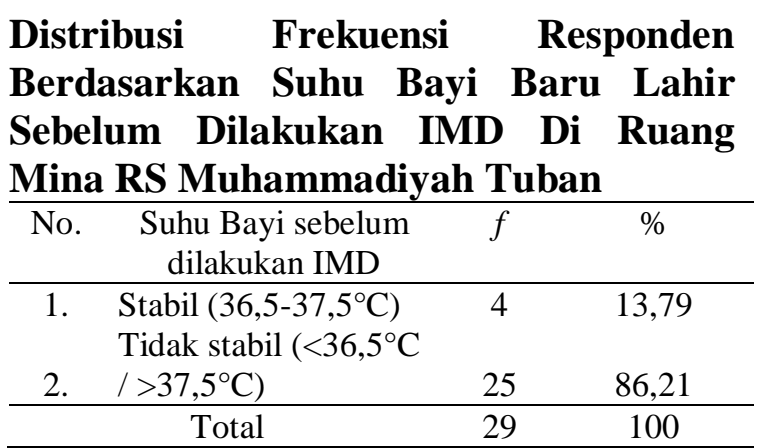

Sumber : Data Primer, 2017

$\overline{\mathrm{x}}: 36,2^{\circ} \mathrm{C}$ Me : $36,3^{\circ} \mathrm{C}$ Mo : $36,4^{\circ} \mathrm{C}$

Menunjukkan bahwa hampir

seluruhnya sebelum dilakukan IMD sebanyak $25(86,21 \%)$ bayi baru lahir mempunyai suhu yang tidak stabil $\left(<36,5^{\circ} \mathrm{C} />37,5^{\circ} \mathrm{C}\right)$.

2. Kestabilan Suhu Tubuh Bayi Baru Lahir Sesudah Dilakukan IMD

\section{Distribusi Frekuensi Responden Berdasarkan Suhu Bayi Baru Lahir Sesudah Dilakukan IMD Di Ruang Mina RS Muhammadiyah Tuban}

\begin{tabular}{cccc}
\hline No. & $\begin{array}{c}\text { Suhu Bayi sesudah } \\
\text { dilakukan IMD }\end{array}$ & $f$ & $\%$ \\
\hline 1. & $\begin{array}{l}\text { Stabil }\left(36,5-37,5^{\circ} \mathrm{C}\right) \\
\text { Tidak stabil }\end{array}$ & 29 & 100 \\
2. & $\left(<36,5^{\circ} \mathrm{C} />37,5^{\circ} \mathrm{C}\right)$ & 0 & 0 \\
\hline & Total & 29 & 100 \\
\hline
\end{tabular}

Sumber : Data Primer, 2017

$\overline{\mathrm{x}}: 36,7^{\circ} \mathrm{C}$ Me : $36,7^{\circ} \mathrm{C}$ Mo : $36,8^{\circ} \mathrm{C}$

Menunjukkan bahwa seluruhnya sesudah dilakukan IMD sebanyak 29 (100\%) bayi baru lahir mempunyai suhu yang stabil $\left(36,5-37,5^{\circ} \mathrm{C}\right)$.

\section{PEMBAHASAN}

\section{Identifikasi Kestabilan Suhu Tubuh Bayi Baru Lahir Sebelum Dilakukan IMD}

Sebelum dilakukan IMD terdapat 25 bayi baru lahir yang hampir seluruhnya memiliki suhu tidak stabil dan hanya terdapat 4 bayi baru lahir yang sebagian kecil memiliki suhu stabil.

Penurunan suhu pada bayi baru lahir terjadi pada menit-menit ke 10-20 setelah kelahiran. Bayi yang masih basah bisa kehilangan panas tubuh yang cukup banyak untuk membuat suhu tubuhnya 
turun sebanyak $2-4{ }^{\circ} \mathrm{C}\left(3,6-7,2{ }^{\circ} \mathrm{F}\right)$. Hal ini disebabkan oleh ketidakmampuan bayi untuk menghasilkan panas yang cukup untuk mengimbangi hilangnya panas saat kelahiran (WHO, 1993).

Pada ruang bersalin dengan suhu 20 $-25^{\circ} \mathrm{C}$ suhu kulit bayi akan turun $0,3^{\circ} \mathrm{C}$ dan suhu tubuh bagian dalam turun $0,1^{\circ} \mathrm{C}$. Selama periode dini setelah bayi lahir biasanya bayi akan kehilangan panas kumulatif $2-3^{\circ} \mathrm{C}$. Kehilangan panas ini terjadi melalui konveksi, konduksi, radiasi dan evaporasi ( Nelson, 2008).

Selain itu bayi baru lahir juga akan kehilangan sebagian besar panas tubuhnya melalui peristiwa evaporasi, konduksi, konveksi dan radiasi (WHO, 1993).

Tingginya jumlah bayi baru lahir yang memiliki suhutidak stabil di Ruang Mina RS Muhammadiyah Tuban yaitu sebesar $25(86,21 \%)$ bayi, keadaan tersebut terjadi karena bayi baru lahir mengalami adaptasi dari suhu didalam uterus ke suhu lingkungan luar yang disebut dengan termoregulasi. Segera setelah bayi lahir, bayi akan berada di tempat yang lingkungannya lebih rendah dari lingkungan dalam rahim. Selain itu, ada faktor lain yang mempengaruhi suhu tubuh bayi yaitu faktor lingkungan seperti ruangan persalinan, dimana saat bayi lahir AC tidak dimatikan sehingga bayi dapat kehilangan panas suhu tubuhnya melalui konveksi yaitu kehilangan panas yang terjadi pada bayi saat terpapar dengan udara sekitar yang lebih dingin contohnya angin dari kipas angin dan penyejuk ruangan tempat bersalin (AC). Apabila bayi dibiarkan bayidapat kehilangan panas melalui empat mekanisme yaitu konveksi, konduksi, radiasi, dan evaporasi, untuk mengurangi kehilangan panas tersebut diatas dapat ditanggulangi dengan mengatur suhu lingkungan, membungkus badan bayi dengan kain hangat dan mempersiapkan tempat kelahiran yang hangat untuk meminimalkan kehilangan panas pada bayi baru lahir.

Bayi baru lahir akan cenderung mengalami penurunan suhu tubuh karena harus beradaptasi dengan suhu lingkungan, keadaan tersebut apabila tidak ditangani bisa menyebabkan bayi mengalami hipothermia,apabila hipothermia ini terjadi maka dibutuhkan penanganan segera agar tidak terjadi komplikasi yang lebih lanjut dengan cara dilakukan penerapan Inisiasi Menyusu Dini (IMD) sesaat setelah bayi lahir dan dilakukan minimal 1 jam, karena cara tersebut dianggap sebagai cara yang paling sederhana dan mudah dilakukan, sehingga diharapkan dapat meningkatkan suhu pada bayi baru lahir.

\section{Identifikasi Kestabilan Suhu Tubuh Bayi Baru Lahir Sesudah Dilakukan IMD}

Sesudah dilakukan IMD seluruh bayi baru lahir memiliki suhu stabil dan tidak satupun bayi yang suhunya tidak stabil.

Suhu dada ibu dapat menyesuaikan suhu ideal yang diperlukan bayi, yaitu dapatturun 10 derajat dan naik sampai 20 derajat Celsius, sehingga dapat menurunkanresiko hipotermia dan menurunkan kematian bayi akibat kedinginan.

Bayi berada dalam suhu yang aman jika melakukan kontak kulit dengan ibu. Suhu payudara ibu akan meningkat 0,5 derajat dalam dua menit jika bayi diletakkan di dada ibu (Maryunani, 2012).

Berdasarkan hasil penelitian Dr. Niels Bergman (2005) ditemukan bahwa suhu dada ibu yang melahirkan menjadi $1{ }^{\circ} \mathrm{C}$ lebih panas dari suhu dada ibu yang tidak melahirkan. Jika bayi yang diletakkan di dada ibu ini kepanasan, suhu dada ibu akan turun $1^{\circ} \mathrm{C}$. Jika bayi kedinginan, suhu dada ibu akan meningkat $2{ }^{\circ} \mathrm{C}$ untuk menghangatkan bayi. Jadi dada ibu merupakan tempat yang terbaik bagi bayi yang baru lahir dibandingkan tempat tidur yang canggih dan mahal.Kulit ibu bersifat termoregulator atau termal sinchrony bagi suhu bayi, dimana ibu menghangatkan suhu tubuh bayi dengan tepat selama merangkak mencari payudara, dan ini akan menurunkan kematian karena kedinginan. 
Bayi yang dilakukan IMD berada dalam suhu yang aman. Karena suhu payudara ibu meningkat $0,5{ }^{\circ} \mathrm{C}$ dalam dua menit jika bayi diletakkan di dada ibu (Roesli, 2012).

Inisiasi menyusu dini (early initiation) adalah proses bayi baru lahir mencari puting susu ibu secara mandiri dengan teknik skin to skin antara kulit ibu dan bayi minimal selama satu jam segera setelah lahir (Saleha, 2009).

Setelah dilakukan Inisiasi Menyusu Dini (IMD) semua bayi baru lahir memiliki suhu tubuh stabil di Ruang Mina RS Muhammadiyah Tuban yaitu sebesar 29 bayi (100\%), hal ini disebabkan karena dada ibu berfungsi sebagai stabilisatorbagi bayi, sehingga dalam pelaksanaannya keterlibatan ibu sangat berperan aktif, dimulai sejak awal sebagai pemberi pelayanan untuk bisa memenuhi kebutuhan fisik dan emosionalnya.

Suhu tubuh bayi baru lahir setelah pelaksanaan IMD berada dalam keadaan stabil, ibu tampak lebih tenang dan bahagia dengan kehadiran bayi didekapannya. Dada ibu yang melahirkan mampu mengontrol kehangatan kulit dadanya sesuai kebutuhan tubuh bayinya, hal ini membuat bayi akan berada pada suhu tubuh yang optimal sehingga bayi merasa lebih tenang dan nyaman, tidak hanya memberikan keuntungan untuk mencegah hipotermi saja, keadaan emosional ibu dan bayi atau ikatan kasih sayang (bonding) antara ibu dan bayi terjalin dengan baik, hal ini akan memberikan dampak yang besar untuk perkembangan bayi, karena ikatan kasih sayang telah terjalin dengan baik, yang pada akhirnya hal tersebut dapat memberikan kontribusi positif dalam meningkatkan kemampuan hidup bayi dan mengembangkan kualitas hidupnya.

\section{KESIMPULAN}

Hasil penelitian yang berjudul "Gambaran Kestabilan Suhu Tubuh Bayi Baru Lahir yang Dilakukan Inisiasi Menyusu Dini (IMD) Di Ruang Mina RS Muhammadiyah Tuban", sesuai dengan tujuan khusus dapat disimpulkan sebagai berikut :

1. Hampir seluruhnya bayi baru lahir memiliki suhu tidak stabil sebelum dilakukan Inisiasi Menyusu Dini (IMD) di Ruang Mina RS Muhammadiyah Tuban.

2. Seluruhnya bayi baru lahir memiliki suhu stabil sesudah dilakukan Inisiasi Menyusu Dini (IMD) di Ruang Mina RS Muhammadiyah Tuban.

\section{SARAN}

1. Bagi Institusi

Supaya memperkenalkan dan digunakan untuk menambah bahan acuan dan pengembangan pengetahuan terhadap ilmu kebidanan dalam menangani masalah suhu tubuh bayi baru lahir.

2. Bagi Peneliti Selanjutnya

Hasil penelitian ini dapat digunakan sebagai bahan acuan dan salah satu pedoman dalam melakukan penelitian selanjutnya mengenai kestabilan suhu sebelum dan sesudah dilakukan Inisiasi Menyusu Dini (IMD), serta mencari dan melengkapi sumbersumber referensi lainnya yang memperkuat dan memperbanyak populasi sehingga hasil yang terkait dengan suhu bayi baru lahir dapat diketahui lebih akurat.

3. Bagi Lahan Praktik

Hasil penelitian ini diharapkan dapat digunakan sebagai masukan dan menambah wawasan tentang bagaimana manfaat Inisiasi Menyusu Dini (IMD) bagi kestabilan suhu tubuh bayi baru lahir, serta diharapkan agar Inisiasi Menyusu Dini tetap diterapkan pada semua bayi baru lahir sesuai dengan prosedur dan untuk meminimalkan kehilangan panas pada bayi karena faktor lingkungan diharapkan ruangan persalinan tetap hangat untuk itu saat bayi 
lahir penyejuk ruangan (AC) agar dimatikan.

\section{DAFTAR PUSTAKA}

Arifin, Sirengar. 2008. Pemberian ASI Eksklusif dan Faktor-faktor yang Mempengaruhinya. Sumatera utara : Universitas Sumatera utara

Arikunto, S. 2010. Prosedur Penelitian. Jakarta : Rineka Cipta

Badan Pusat Statistik Provinsi Jawa Timur. 2015. SDKI. Jakarta : Badan Pusat Statistik

Depkes, RI. 2015. Profil Kesehatan Indonesia Rakorpop Kementerian Kesehatan RI Jakarta, 1 Desember 2015. Jakarta : Depkes

Guyton, Arthur C. 2008. Buku Ajar Fisiologi Kedokteran. Jakarta : EGC

Kemenkes, RI. 2011. Penelitian IMD. Jakarta : Depkes

Kokom (2007). Kematian Bayi. Akses Rabu 3 Januari 2007. http://www.goegle.com

Latif, Abdul. 2007. Pendidikan Berbasis Kemasyarakatan. Bandung : Refika Aditama

Maryunani, Anik. 2012. Inisiasi Menyusu Dini, ASI eksklusif, dan Manjemen Laktasi. Jakarta : Trans Info Media

Nazir, Moh. 2007. Metode Penelitian. Jakarta : Ghalia Indonesia

Nelson, Behmen Dkk. 2008. Ilmu Kesehatan Anak Nelson Edisi $15 \mathrm{Vol}$ 2. Jakarta : EGC

Notoatmodjo, Soekidjo. 2010. Metodologi Penelitian Kesehatan. Jakarta : Rineka Cipta
Nurheti. 2009. Keajaiban ASI, Yogyakarta : Andi Offset

Nursalam. 2008. Konsep dan Penerapan Metodologi Penelitian Ilmu Keperawatan. Jakarta : Salemba Medika

Potter, P.A. \& Perry. A.G.2008. Buku Ajar Fundamental Keperawatan : Konsep, Proses, dan Praktik, Edisi 4, Volume II. Jakarta : EGC

Prawirohardjo, S. 2011. Ilmu Kebidanan. Jakarta : PT Bina Pustaka Sarwono Prawirohardjo

Roesli, Utami. 2007. Inisiasi Menyusu Dini Plus ASI Ekslusif Cetakan I. Jakarta : Pustaka Bunda

Rosita, S. 2008. ASI Untuk Kecerdasan Bayi. Yogyakarta: Ayyana

Saleha, Sitti. 2009.Asuhan Kebidanan Pada Masa Nifas. Jakarta: Salemba Medika

Siswosuharjo, Suwignyo \& Fitria Chakrawati. 2010. Panduan Superlengkap Hamil Sehat. Semarang : PENEBAR Plus +

Sugiyono. 2010. Memahami Penelitian Kualitatif. Bandung : Alfabeta

Tambayong. 2007. Anatomi Fisiologi Untuk Keperawatan. Jakarta : Rineka Cipta

Vivian, Nanny Lia. 2010. Asuhan Neonatus Bayi dan Anak Balita. Jakarta : Salemba Medika

WHO / UNICEF. Initiation Of Breasfeeding By Breast Crawl. New Delhi : Unicef

WHO (1996). Essential Newborn Care. WHO/FRH/MSM/96.13. 
Jurnal Kebidanan Universitas Islam Lamongan ISSN 2086-2792 (Print)

Vol. 10 No. 1, Juni 2018

WHO (1993). Thermal Control Of The Newborn: A Practical Guide. WHO/FHE/MSM/93.2.

WABA. 2008. Pedoman Pelaksanaan Pekan ASI Sedunia, Worlk Alliances For Breastfeeding Action (WABA). Jakarta : Depkes 